\title{
PERFORMANCE OF NATURAL FIBER REINFORCED PLASTIC
}

\author{
Vishwajith Kaushik R, Vigneshwaran S, Joseph S and Bharath Shakthivel BR \\ Final Year, Department of Automobile Engineering, \\ Easwari Engineering College, Chennai, Tamil Nadu, India
}

\begin{abstract}
Natural fibers could be a great alternative to glass fiber reinforced composites especially in automotive applications. Traditionally used natural fibers are now becoming one of the fastest growing performance additives for thermoplastics. Advantages of natural fibers over conventional glass fiber are: low cost, low density, favorable mechanical properties, reduced energy consumption, biodegradability. The combination of natural fibers like Hemp, Flax, Jute, Henequen, Pineapple leaf fiber and Sisal (hybrid combinations) with polymer matrices produce composite materials which are on par with (in terms of performance and quality) synthetic composites. The vehicle bodies made from these materials give high performance while being entirely biodegradable. Using natural fibers with polymers based on renewable resources will allow many environmental issues to be solved.
\end{abstract}

Keywords: Fiber reinforced plastic, natural fibers, biocomposite

Cite this Article: Vishwajith Kaushik R, Vigneshwaran S, Joseph S and Bharath Shakthivel BR, Performance of Natural Fiber Reinforced Plastic. International Journal of Mechanical Engineering and Technology. 11(6), 2020, pp. 37-40.

https://iaeme.com/Home/issue/IJMET?Volume $=11 \&$ Issue $=6$

\section{INTRODUCTION}

Fiber Reinforced Plastics has emanated as the best alternative material for reinforcing steel and concrete structures. It is used as a replacement for steel in especially harsh conditions due to it's lightweight, elasticity, resistance to corrosion, dimensional stability, low thermal conductivity, no conductivity, electromagnetic transparency, impact resistance and low life cycle costs. The disadvantages of the FRP composites are high initial costs, their susceptibility to mechanical damage and fire, inability to bend in the field, longer load transfer lengths, poor shear strength and low strain to failure. Due to other differences in the physical and mechanical behaviour of the FRP materials versus steel, unique guidance on the construction of concrete structures reinforced with FRP bars is needed. [1] Another major disadvantage is the use of synthetic polymers and glass fibers which are non-biodegradable and harmful to the environment. 


\section{CONSTITUENTS OF FRP}

The composites consist of two components: fibres and matrix. The fibres create $30 \%$ to $70 \%$ from the volume of the composite and $50 \%$ of its weight. The main objective of fibres are to bear the load and provide stiffness, strength, thermal stability and other structural attributes to the FRP. [2] The fibres in FRP composites must have high modulus of elasticity, high ultimate strength, low variation of strength among fibres, high stability of their strength during handling and high uniformity of diameter and surface dimension among fibres. The matrix assures the arrangement and alignment of the fibres, protection from damage during manufacture and durability of the composite as well as the protection from the harsh environment. It is also responsible for the distribution of the loads on the individual fibres.

\subsection{Nature of Polymers Conventionally used in FRP}

The linking of small molecules (monomers) to make larger molecules is a polymer. Polymerization requires that each small molecule have at least two reaction points or functional groups. The polymer chains can be classified in linear polymer chain, branched polymer chain, and cross-linked polymer chain. The polymers widely used for manufacturing FRP are synthetic in nature. It is non-biodegradable. Polycarbonate (plastic) and epoxy resins (coating and adhesive) are normally produced with bisphenol A as one of the monomers.[3] This substance may also be used as an additive for plastics. It is an endocrine disruptor (it can mimic hormones). Some studies have shown toxicity, carcinogenic effects and possible neurotoxicity at low doses in animals [4]. During the decomposition of the resin, this toxic monomer could be released into the environment.

\subsection{Nature of Fiber Conventionally used in FRP}

Two of the most widely used fibers in FRP are Carbon fiber and glass fiber.

\subsubsection{Glass Fiber}

Fiberglass is classified as a group of products made from individual glass fibers combined into a variety of forms. Glass fibers can be divided into two major groups with respect to their geometry: continuous fibers used in yarns and textiles, and the discontinuous fibers used as batts, blankets, or boards for insulation and filtration. Fiberglass can be contrived into yarn much like wool or cotton, and woven into fabric which is occasionally used for draperies. Fiberglass textiles are commonly used as a reinforcement material for molded and laminated plastics.The basic raw materials for fiberglass products are a variety of natural minerals and manufactured chemicals. The primary ingredients are silica sand, limestone, and soda ash. Other ingredients may include calcined alumina, borax, feldspar, nepheline syenite, magnesite, and kaolin clay, among others. Silica sand is used as the glass former, and soda ash and limestone help mainly to decrease the melting temperature. Other ingredients are used to improve certain properties, such as borax for chemical resistance. [5]

\subsubsection{Carbon Fiber}

Carbon fiber is produced from organic polymers, which consist of long strings of molecules held together by carbon atoms. Most carbon fibers are made from the polyacrylonitrile (PAN) process. A small amount is manufactured from rayon or the petroleum pitch process.

Liquids, gases and other materials used in the manufacturing process generate distinct effects, qualities, and grades of carbon fiber. Carbon fiber manufacturers use custom formulas and combinations of raw materials for the materials they produce. These two commonly used fibers are not eco-friendly. The waste produced by these materials take a lot of time to decompose. 


\section{BIODEGRADABLE POLYMER}

During the 1960s percipient environmentalists became aware that the increase in volume of synthetic polymers, particularly in the form of one-trip packaging, presented a potential threat to the environment, what became evident in the appearance of plastics packaging litter in the streets, in the countryside and in the seas [6].

To avoid this we can use biopolymers. Biopolymers are produced by living organisms. They have existed on our planet for many years, and for this reason micro-organisms have had enough time to develop enzymes capable of degrading their structure. In short their environmental impact is low. Biopolymers can be easily produced by using natural resins and starch.

\subsection{Biodegradable Fiber}

The next issue we need to tackle is finding a substitute to the fibers used in FRP. Instead of using synthetic fibers we can use natural fibers like jute, coir, straw etc., We can get a clear view of their practical application based on their physical properties. Generally two or more of the fibers in combination to get the desired properties.

A composite material (also known as composition material) made from two or more constituent materials with significantly varying physical or chemical properties that, when combined, yields a material with properties different from the individual components. The individual components remain separate and discrete within the completed structure, differentiating composites from mixtures and solid solutions. The new material may be preferred for many reasons : Common examples include strength, light weight, lost cost etc.,

\section{EXPERIMENT}

A rod of the same diameter and length are used. They are made using a standard resin but different fibers in the matrix. A two point flexural test is conducted to obtain the flexural strength. Then a tensile specimen is made for the tensile testing. The results of the two tests are documented.

Table 1 The properties of fibers used in the experiment [7]

\begin{tabular}{|l|c|c|c|c|}
\hline \multicolumn{1}{|c|}{ Properties } & Glass & Jute & Coir & Sisal \\
\hline Density (g/cm3) & 2.567 & 1.47 & 1.25 & 1.34 \\
\hline $\begin{array}{l}\text { Tensile Strength } \\
\text { (N/mm2) }\end{array}$ & 2450 & $400-800$ & 220 & $600-700$ \\
\hline Stiffness (KN/mm2) & 72 & $10-30$ & 7 & 38 \\
\hline $\begin{array}{l}\text { Elongation at break } \\
(\%)\end{array}$ & 3 & 1.8 & $15-25$ & $2-3$ \\
\hline Moisture Absorption & - & 12 & 10 & 11 \\
\hline
\end{tabular}

\section{RESULTS AND DISCUSSIONS}

The results of the tests show that the glass fiber has superior mechanical properties when compared to the natural fibers but the composite material which is a combination of different organic fibers improved the result substantially. 


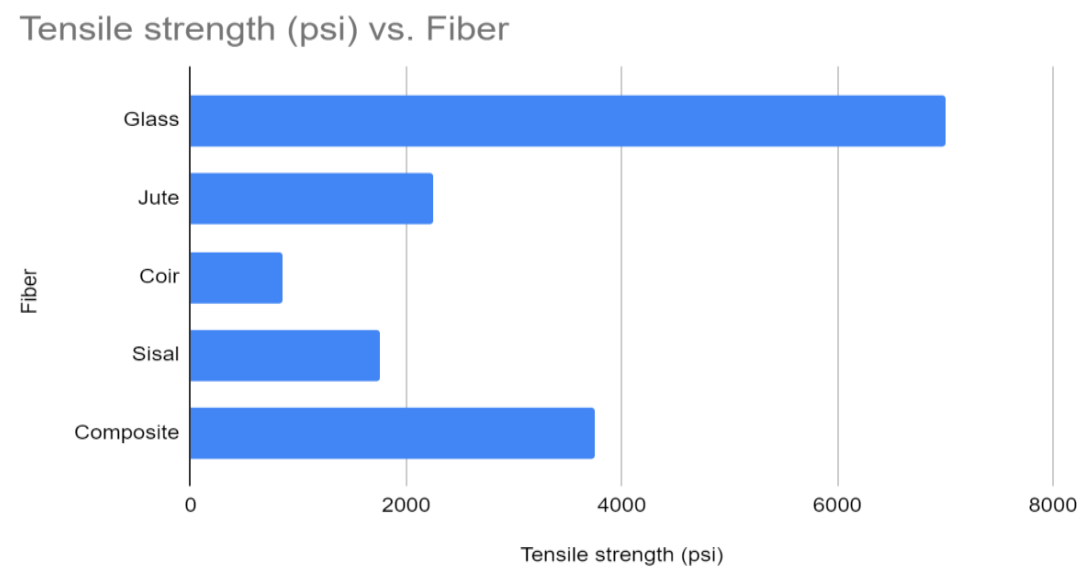

Figure 1 Tensile strength of FRPs with individual fiber matrix

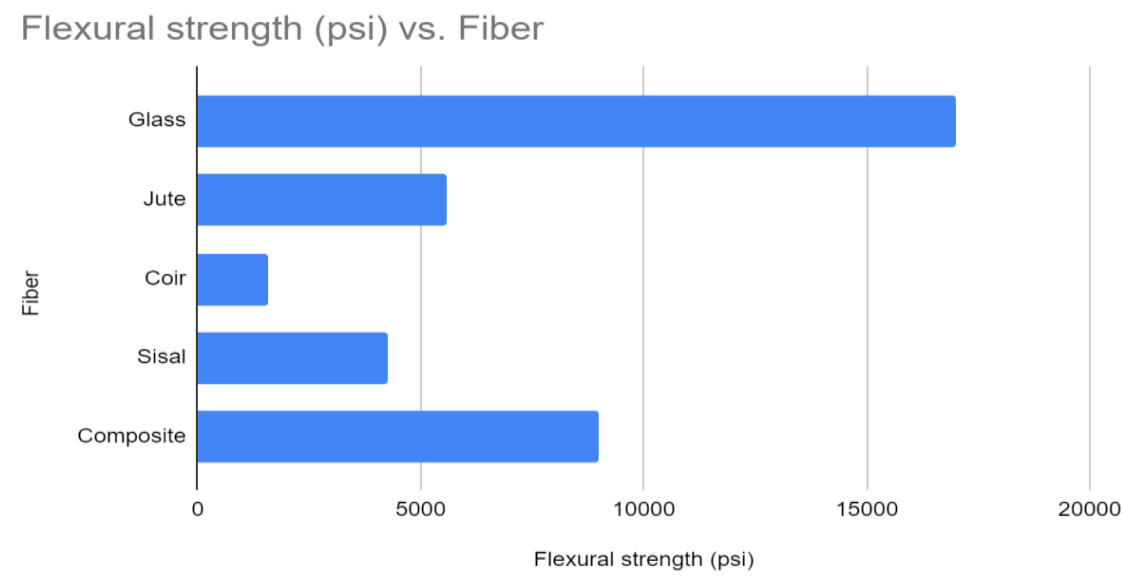

Figure 2 Flexural strength of FRPs with individual fiber matrix

\section{CONCLUSION}

The environmental complications caused by conventional Fiber reinforced plastics is obvious, but FRP is also an indispensable resource, so the best course of action would be to manufacture them using biodegradable and eco-friendly polymers and fibers. Combining different natural fibers gives more desirable properties to the FRP.

\section{REFERENCES}

[1] Potyrala P. B., 2011. Use of Fibre Reinforced Polymer Composites in Bridge Construction. Universitat Politécnica de Catalunya.

[2] Tuakta C., 2005. Use of Fiber Reinforced Polymer Composite in Bridge Structures, Massachusetts Institute of Technology

[3] ScottG 1999 Polymer and the environment. Cambridge: RSC Paperbacks. 132p.

[4] SotoA. MSonnenschein C 2010Environmental causes of cancer: endocrine disruptors as carcinogens. Nature Reviews Endocrinology 67363370

[5] Aubourg, P.F., Crall C., Hadley J., Kaverman R.D., and Miller D.M. Glass Fibers, Ceramics and Glasses. Engineered Materials Handbook, Vol. 4. ASM International, 1991, pp. 1027-31.

[6] A N. Abilash and B M. Siva pragash (2013), Environmental benefits of ecofriendly natural fiber reinforced polymeric composite materials, International journal of applications or innovation in engineering \& management, volume 2 , issue 1, page 53-59 